\title{
Relations between animal transgenesis and reproduction
}

\author{
Louis-Marie HoUDEBINE* \\ UMR Biologie du Développement et Reproduction, Institut National de la Recherche Agronomique, \\ 78352 Jouy-en-Josas Cedex, France
}

\begin{abstract}
Transgenesis has become an essential tool for the study of gene expression mechanisms and functions. Transgenesis is also more and more used for biotechnological applications such as the study of human diseases, the adaptation of pig organs to humans, the production of pharmaceutical proteins in milk and likely in the future for the improvement of animal production. The use of transgenesis relies on the efficiency of gene transfer. New tools have been recently designed to improve gene transfer. The methods of gene transfer are highly dependent on the techniques of animal reproduction. Conversely, the need to improve transgenesis urges researchers to study some of the key steps in reproduction and to find new techniques for gene transfer. This paper summarises the recent data and the perspectives offered by animal transgenesis.
\end{abstract}

transgenesis / animal production / biotechnological applications

\section{INTRODUCTION}

The first demonstration about 30 years ago that it was possible to isolate genes, to recombine DNA fragments in vitro and to introduce native or recombinant genes into bacteria was rapidly followed by the expression of foreign genes after transfection into animal cells. The idea of reintroducing a gene in the genome of animals appeared logical, quite attractive but not easily feasible in a short term.

The demonstration in 1980 that foreign genes could be integrated into the mouse genome and transmitted into progeny was a great technical and symbolic event for the scientific community. This initial success was repeated and followed two years later by the generation of transgenic mice harbouring foreign growth hormone genes and showing a greatly enhanced growth. The proof was given for the first time that foreign genetic information could be expressed and induce specific phenotypic effects. Broad perspectives for basic research and biotechnological applications in the medical and agronomical fields appeared open. The fact was perceived not only by the scientific community but also by citizens. Yet, it took years before a number of biologists

\footnotetext{
* Corresponding author: houdebin@jouy.inra.fr
} 


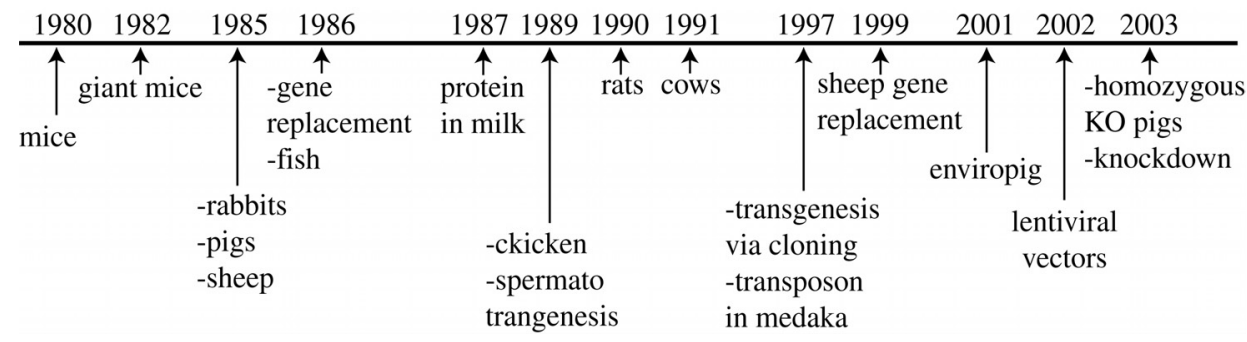

Figure 1. The different key steps in animal transgenesis.

not familiar with molecular approaches realised that they were living a technical and methodological revolution. Until the end of the 1980's, some biologists remained convinced that transgenic mice became giant because they received growth hormone genes from species (rats and humans) larger than themselves. Similarly, it took time before some biologists admitted that a more molecular approach including transgenesis was highly beneficial to the study of biological functions.

In 1985, transgenic rabbits, pigs and sheep were obtained indicating that the techniques originally defined for mice could be extended to other mammals. In 1986, the first transgenic fish were obtained using DNA microinjection into the cytoplasm of embryos rather than the pronuclei which are not visible in these species.

The first success of transgenesis appeared sooner than anticipated. It was the result of a multidisciplinary approach including embryology, biology of reproduction, molecular biology and genetic engineering. Transgenesis is now achieved in mammals including farm animals and in a near future in pets, as well as in vertebrates and invertebrates. About 25 animal species are presently used to develop transgenic lines for basic research or applied purposes (Fig. 1).

Since the invention of agriculture and breeding, genetic selection relies on the observation of living organisms followed by the preferential reproduction of some of them. The same became true more recently for laboratory animals used to study biological and gene functions as well as human diseases.

Modern biology relies more and more on the systematic generation of lines of living organisms having phenotypical characteristics followed by the identification and the study of the genes responsible for the observed biological properties of these individuals. A broader biodiversity is currently being created by inducing random mutations using chemical mutagens or irradiation. This procedure is now being extended to a mammal, the mouse, giving rise to relevant models but remaining highly imprecise. In plants, interspecies crossing is currently leading to the generation of new varieties and even to new species.

Transgenesis offers unprecedented possibilities. It is more precise, since essentially only one or a few known genes are being modified in a genome and foreign genes can be introduced in a given species (Fig. 2).

Transgenesis is a more and more used technique. It offers the possibility to study and use the newly discovered genes which are becoming more and more numerous with the systematic sequencing of genomes (Fig. 3).

From the beginning, the success of transgenesis is highly dependent on the control of reproduction. Each group of species raises different problems, specially for gene transfer. It is noteworthy that gene transfer implies, according to species, superovulation, in vitro maturation and fertilisation including 


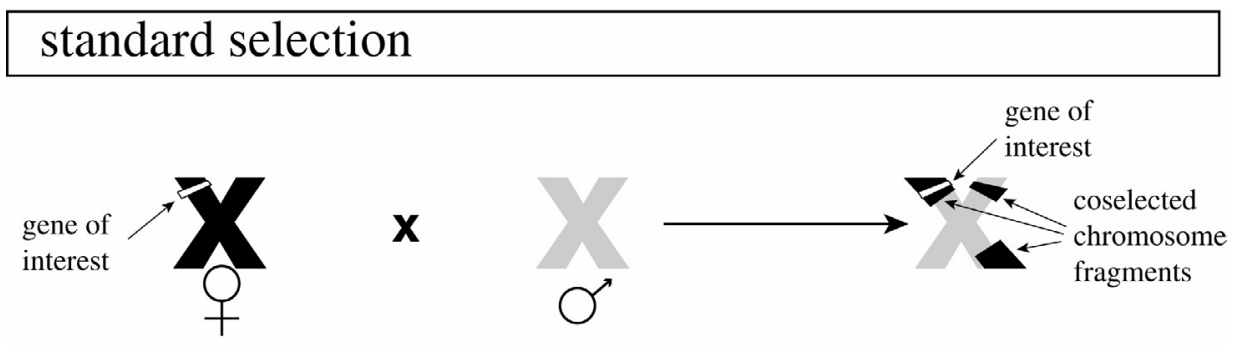

\section{transgenesis}

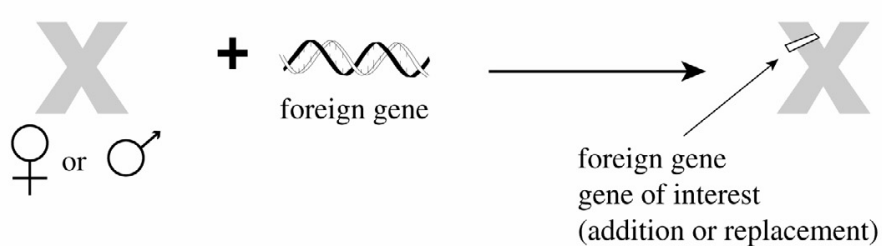

Figure 2. Comparison of classical selection based on sexual reproduction with transgenesis. In classical selection, the experimenters ignore the nature of the selected gene of interest and of the coselected genes which may have deleterious effects. In transgenesis, the foreign gene is known and brings a single genome modification which may be studied in detail.

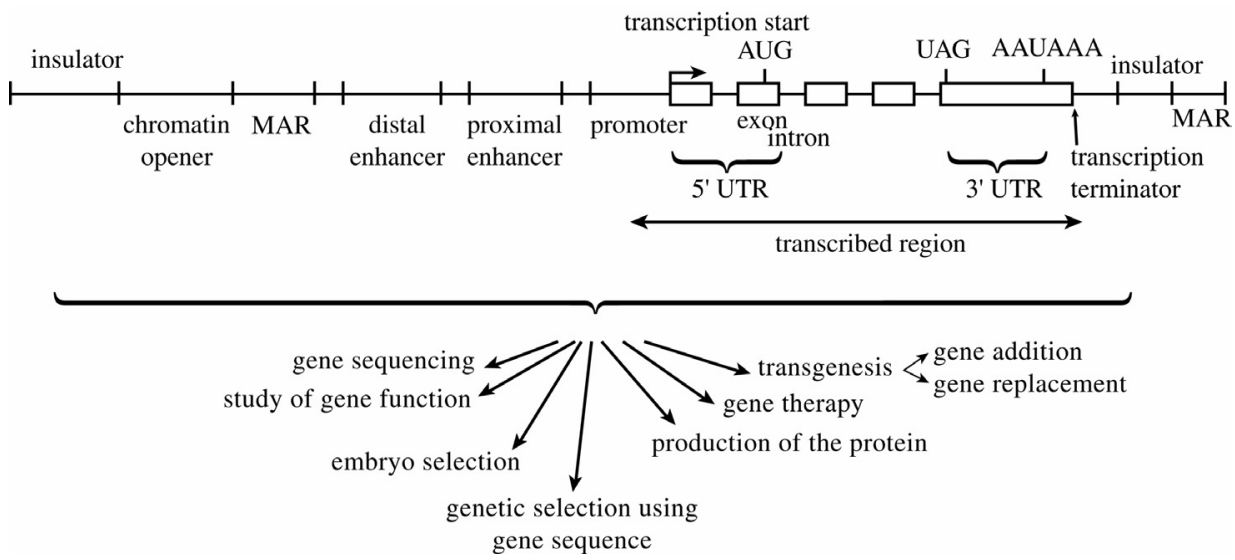

Figure 3. Consensus structure and the different utilisations of eucaryotic genes.

ICSI, cloning by nuclear transfer, generation of chimerae by blastomere transfer, gene transfer into seminal tubules, collect and reimplantation of spermatocytes after gene transfer, embryo culture and embryo transfer. 
Clearly, a progress in the techniques of reproduction may facilitate transgenesis. Conversely, transgenesis is quite difficult to achieve by DNA microinjection into pronuclei in some species such as ruminants. This urged researchers to develop alternative techniques. The birth of Dolly the sheep was achieved with the aim of facilitating gene transfer. Similarly, sperm manipulation is being improved not only to describe spermatogenesis and fertilisation but also to tentatively offer new ways of gene transfer. Transgenesis thus accelerates some specific studies in biology of reproduction. More marginally, reproduction may indirectly take advantage of transgenesis. One example is the preparation of large amounts of bovine FSH and possibly of human FSH and other hormones in the milk of transgenic animals.

Animal transgenesis is presently facing three major problems (i) gene transfer to generate transgenic lines, (ii) reliable expression of transgenes, (iii) interpretation of the data obtained with transgenic animals. The first two problems are essentially technical whereas the third is inherent to the approach which consists of returning a simple gene back to its natural complexity.

This paper is a brief survey of animal transgenesis. A more detailed description of the techniques and applications of transgenesis has been reported in a book [1].

\section{TECHNIQUES OF GENE TRANSFER}

Unless genes are included in viral particles, they cannot penetrate spontaneously into cells. Their large size, their ionic charge and their sensitivity to surrounding DNAse preclude spontaneous DNA transfer into cells and embryos. Various methods have been designed to transfer foreign DNA. Before describing these methods, it is important to consider the mechanisms involved in foreign DNA integration into genomes.

\subsection{The fate of foreign DNA}

When added into a nucleus, a linear foreign DNA is circularised, randomly cleaved and associated according to a homologous recombination process, generating perfectly matched polymers in which genes are in tandem arrays.

When added into cytoplasm (after transfection, electroporation or microinjection), DNA fragments are randomly associated forming tandem or head to tail polymers with some rearrangements.

Part of the DNA migrates to the nucleus.

Foreign genes in the nucleus can be transiently expressed and are destroyed during the next cell replication unless they are integrated.

Foreign DNA are randomly digested by exonucleases which generate single strand ends capable of recognising similar but usually not identical sequences in the genome. This leads to random integration of the foreign DNA. Alternatively, foreign DNA can replace an identical host DNA region according to a homologous recombination process. This leads to host gene inactivation (knock out) if the foreign gene construct is an inactive gene. This leads to the expression of a mutant or a quite different gene (knock in) if the foreign gene construct is a functional gene.

Homologous recombination is a rare event $(0.1-1 \%)$ of heterogeneous recombination. Gene replacement must therefore be achieved in cells which are selected and further used to generate an embryo.

\subsection{DNA microinjection}

DNA can be microinjected into the pronuclei of mammals only. In other species, the vitellus and the shell do not allow a visualisation of the pronuclei. Microinjection must then be achieved into the cytoplasm. About 1 000-5 000 and 1-20 million copies are injected into the pronuclei and the cytoplasm respectively. 
For unknown reasons, the integration rate is highly variable according to species. Up to $1-3 \%$ of microinjected embryos may become transgenic mice whereas the rate is lower for rabbits, rats, pigs and extremely low in ruminants. Integration essentially does not occur in chicken, xenopus and medaka embryos (although it is relatively high in other fish species such as salmonids).

In order to improve integration, the foreign genes may be inserted into transposons. For this purpose, the integrase gene of the transposon is deleted to make space for the foreign genes and to prevent the recombinant transposon to disseminate in the genome autonomously. To become integrated, the recombinant and defective transposon must be complemented by exogenous integrase either comicroinjected with the transposon or synthesised from a plasmid harbouring the integrase gene.

A variety of transposons are being implemented according to species. Transposon $\mathrm{P}$ is extensively used to generate transgenic Drosophilae. The transposons Sleeping Beauty and piggy Bac are used for a number of species [2] and for the silk worm [3] respectively. Other transposons are used for various species of insects.

Transposons are efficient and safe but they can harbour no more than $3-4 \mathrm{~kb}$ of foreign DNA.

\subsection{Use of retroviral vectors}

Retroviral vectors are extensively studied to transfer genes to somatic cells of patients. These vectors have met some success particularly to allow immunodeficient children to leave their protective bubbles. These vectors have been recently improved using lentiviral genomes and an envelope from the vesicular somatitis virus. High concentrations of particles can be obtained. These vectors can infect all cell types and they transfer their genetic material to the host genome in quiescent as well as in replicating cells [4].
Foreign genes inserted into lentiviral vectors are also generally not silenced as opposed to those transferred by conventional retroviral vectors.

These vectors have proven highly efficient in generating transgenic mice [4], pigs [5], cows [6], chickens [7, 8] and sheep [9].

For unknown reasons, lentiviral vectors have to be injected into the oocyte in order to generate transgenic cows whereas injection into a one cell embryo is preferable in most other species (Fig. 4).

Lentiviral vectors are much more efficient than classical microinjection in some species such as ruminants or chickens. One limitation is that lentiviral vectors can harbour at most $8.5 \mathrm{~kb}$ of foreign DNA. This may be hardly enough in some cases.

\subsection{Use of sperm cells to transfer genes}

Experiments carried out more than one decade ago showed that sperm incubated in a DNA solution can transfer the foreign gene into the oocyte during fertilisation. This extremely simple technique gave birth to transgenic animals of different species. The method which originally appeared poorly reproducible has been greatly improved by eliminating the DNAse which is abundant in seminal plasma and on the sperm surface [10].

This approach has been improved by initially degrading the sperm membrane. This allows DNA to penetrate abundantly into the sperm but precludes spontaneous fertilisation. ICSI (intracytoplasmic sperm injection) is then required to fertilise oocytes with the damaged sperms. This technique was initially defined to generate transgenic xenopus. It has been successfully extended to other species. Interestingly, the most recent publications indicate that the efficiency can be greatly improved by modifying the protocol and also that DNA fragments as long as $200 \mathrm{~kb}$ can be transferred into embryos with a good yield and without any degradation of the DNA. This suggests that ICSI could be used more 


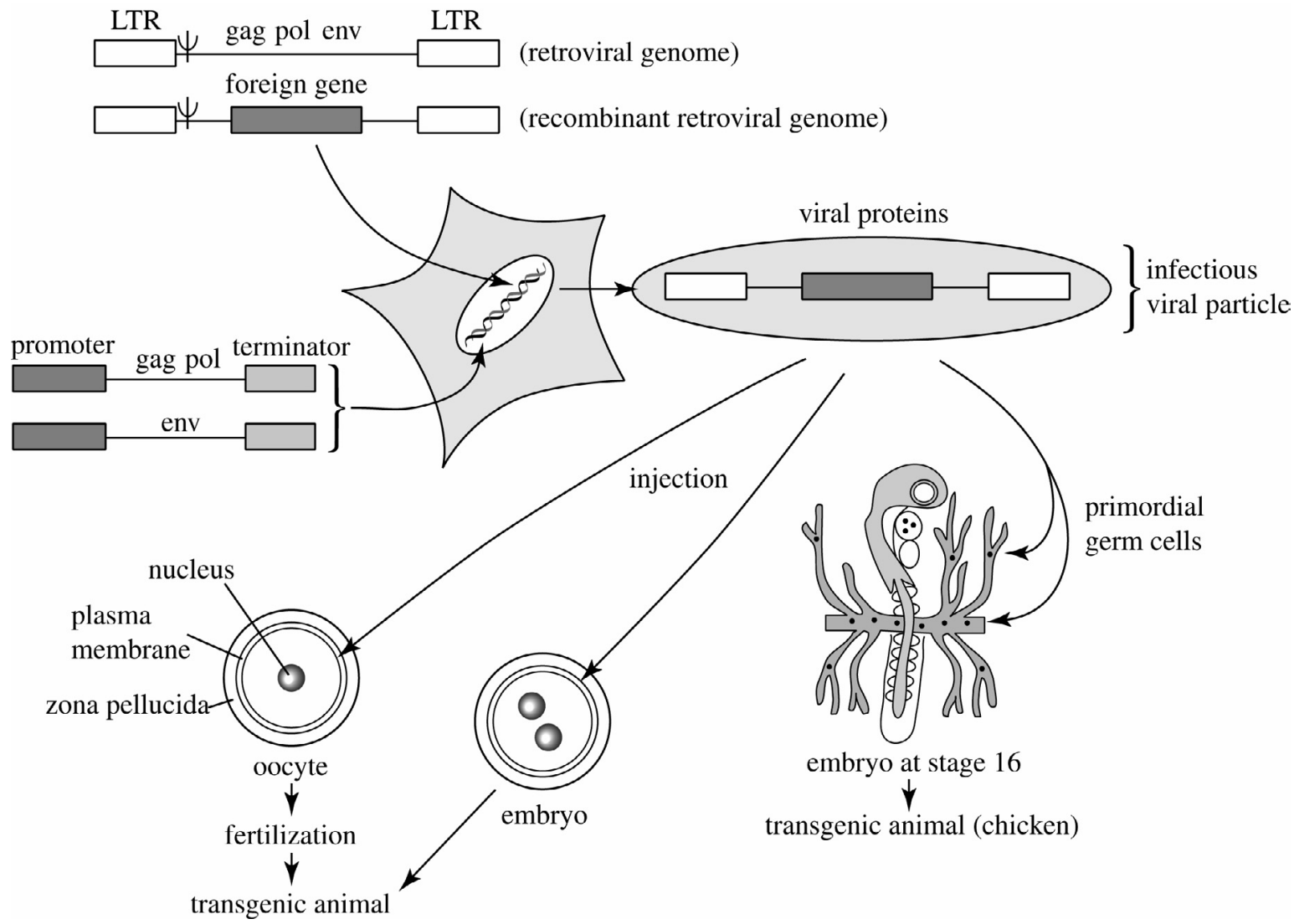

Figure 4. Gene transfer into oocyte, embryo or primordial germ cells using lentiviral vectors. The viral proteins are provided to the defective viral genome harbouring the foreign gene by a transcomplementing cell. 
broadly to generate transgenic animals in a variety of species [11-13].

An elegant method which is being used by one group consists of incubating sperm with an antibody which specifically recognises a surface antigen. This antibody also has in its $\mathrm{C}$ terminal part a stretch of basic aminoacids that spontaneously binds DNA. The sperm-antibody DNA complex was used to generate transgenic mice, pigs and cows with good efficiency $[14,15]$.

Foreign DNA can be transferred directly into sperm precursors by injecting DNAtransfectant complexes into seminal tubules [16]. Alternatively, sperm cell precursors may be collected, transfected in vitro and reimplanted into recipient testis [17, 18]. This allows gene addition and potentially gene replacement using homologous recombination.

\subsection{Use of chimaeric animals}

One way to generate living genetically modified animals with cells in which gene addition or gene replacement has been achieved consists of using the capacity of pluripotent cells to participate to development after having been injected into a blastocyst. In the best cases, the resulting animals are mosaic for the transgene which is present in germinal as in somatic cells. This allows the further generation of lines of animals homozygous for the genetic modification [19].

Although relatively laborious, this approach allowed to knock out more than 5000 genes in mice. This technique provides researchers with a wealth of information. In a number of cases, the data obtained with these knock out animals cannot be easily exploited since the homozygous animals are not viable or show no phenotypic modification.

This elegant method is still restricted to two lines of mice. In other lines as in other species, despite an intense effort, pluripotent cells capable of transmitting their genome to progeny have not been estab- lished. The reason why the two mouse lines allow the use of ES (embryonic stem cells) to generate chimaeric animals with germinal transmission is not known. This raises the question of knowing what is a pluripotent ES cell. Several genes involved in the maintenance of the pluripotent state of cells have been identified and others are under study. These genes are transfected into cells of early embryos from mice and other species with the hope that this will allow the establishment of ES cell lines and their use to knock out genes.

\subsection{Use of cloned animals}

To circumvent the lack of utilisable ES cells, the cloning technique has been implemented. In practice, it consists of adding a foreign gene or replacing an endogenous gene by homologous recombination in fetal somatic cells and using their nuclei to generate cloned transgenic animals.

Gene addition was achieved soon after the birth of Dolly. This approach has been adopted by all the groups working with ruminants. Indeed, although laborious, gene transfer is easier and quite significantly more efficient by cloning than by classical microinjection in these species.

Gene replacement by homologous recombination can be presently achieved in species other than mice only by implementing the cloning technique. This remains a difficult task for several reasons. Homologous recombination is less frequent in somatic than in pluripotent cells. On the contrary, the selection of the cells in which gene replacement has occurred is a relatively long process implying the use of antibiotics. These conditions of culture, alter cells in an unknown manner rendering a successful cloning less likely.

Gene replacement by cloning was initially achieved in sheep [20] and soon after in mice. Interestingly, the galactosyl transferase gene in the pig has been knocked out in this manner with no major difficulty [21, 22]. For an unknown reason, pig cells are 


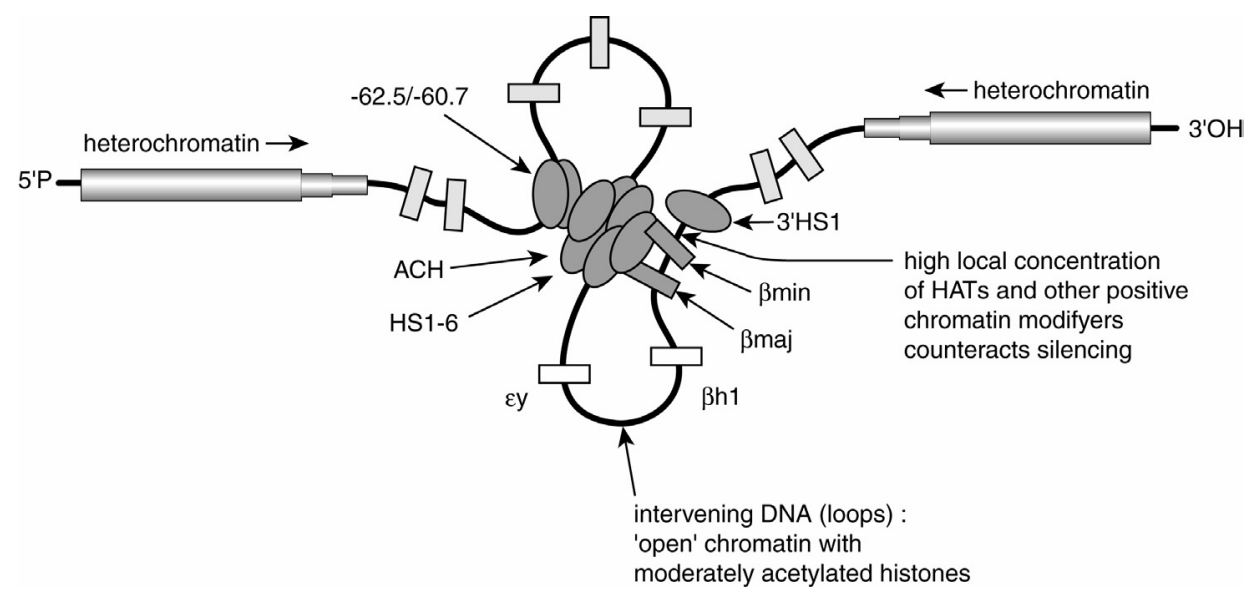

Figure 5. The mechanism of action of insulators. Remote regulatory elements are concentrated in a hub thanks to the formation of loops. The factors concentrated in the hub maintain an open chromatin conformation by hyperacetylating histones. This allows an efficient gene expression.

less sensitive than ruminant cells to factors which reduce cloning efficiency.

A recent study has shown that it is possible to knock out both alleles of two genes in the same cow. To reduce the artefacts of cloning, the authors of this work knocked out a first allele and used cells of the resulting foetus to knock out the second allele. This protocol was followed to inactivate both alleles of a second gene [23]. The passage to the foetal state gives the best chance to eliminate the clones that will have the less chance to survive.

Interestingly, one of the knock out genes here codes for PrP, the protein which plays a major role in bovine prion disease.

\section{VECTOR DESIGN FOR TRANSGENE EXPRESSION}

Genes contain multiple signals in their transcribed as in their promoter regions. These signals are not all known and their association in gene constructs leads frequently to poorly active transgenes.

After more than two decades, empirical rules to design vectors which express transgenes efficiently have emerged. Transgenes are poorly expressed when they contain no introns, when they are rich in $\mathrm{CpG}$ regions and when they are integrated in tandem arrays [24]. Strategies of gene construction must therefore take these observations into account to augment the chance of transgene expression.

It is now clear that in eucaryotic genomes, genes are generally clustered forming loci which are bordered by insulators. Insulators which may be located 10 $50 \mathrm{~kb}$ or more from the genes have several known functions and likely others which remain to be discovered.

They contain enhancer blockers which prevent the gene regulators of a locus to interact with the genes of the neighbouring loci. Insulators also contain elements capable of locally maintaining chromatin in an open configuration (euchromatin). This is achieved with chromatin factors which favour histone hyperacetylation and prevent DNA methylation (Fig. 5).

The existence of insulators was revealed by the fact that some patients suffering from thalassemia had a non-mutated $\beta$-globin gene and promoter but a deletion of a far upstream region. Moreover, this region 
known as LCR (locus control region) or insulator allows a reliable expression of the $\beta$-globin gene in transgenic mice. The same gene remains silent when it is not associated with the LCR.

In about 20 cases, long DNA genomic fragments allow a reliable expression of the transgene they contain. These long DNA fragments may be used as vectors to express associated foreign genes. Likely, in a few years, BAC vectors containing long DNA fragments allowing efficient transgene expression in a variety of cell types will be available. It is also conceivable that the elements forming insulators will be identified and concentrated into compact structures capable of preventing interactions of chromatin and transgenes. This would allow reliable transgene expression but also no deleterious activation of host genes (such as oncogenes) by the enhancers added in the transgene constructs. In the mean time, fragments of insulators may improve transgene expression [25].

\subsection{Use of RNAi to knock down genes}

Fortuitous observations have shown that, unexpectedly, double strand RNA inhibit much more potently mRNA sharing the same sequence than single strand RNA. The essential of the involved mechanisms has been deciphered. Long double strand RNA are randomly cleaved into $21-23 \mathrm{bp}$ fragments which are associated with a protein complex which allows specific recognition and degradation of the mRNA having similar sequences (Fig. 6) [26, 27].

This small RNA known as interfering RNA (siRNA or RNAi) may be transfected to cells or synthesised by appropriate vectors.

Transgenic mice in which the ski gene has been knocked down by a RNAi show similar biological characteristics to those observed in mice in which the ski gene has been knocked out by homologous recombination [28].

Double strand RNA show a more or less potent interfering effect according to the targeted sequence consensus sequences recently discovered [26]. The extensive use of RNAi in cells, tissues and transgenic animals to inhibit endogenous or viral genes appears more and more attractive.

The advantage of gene knock down over knock out is its relative simplicity, its flexibility and its reversibility.

Vectors allowing an inducible and reversible induction of RNAi synthesis in transgenic animals are under study and should be available in the coming years.

Short double strand RNA can also specifically inhibit gene expression by inducing a DNA methylation in the promoter region. This phenomenon known as TGS (transcriptional gene silencing) which is different from mRNA degradation (PTGS: posttranscriptional gene silencing) is irreversible and even transmitted to progeny $[29,30]$.

The expression of a gene may be blocked not only at the DNA or mRNA levels but also at the protein level. Overexpression of a non-secreted antibody in transgenic animals may inhibit the cellular protein recognised by the antibody [31].

Another possibility consists of overexpressing a transdominant protein. A recent study may exemplify this approach. A secretion of the soluble region of pseudorabbies virus responsible for Aujeszky disease in transgenic mice used as models prevents infection by the virus. The virus is unable to make a distinction between the normal receptor on cells and the soluble binding site. The virus is thus trapped by the overexpressed soluble receptor and becomes unable to infect cells and animals. Generation of transgenic pigs resistant to Aujeszky disease is now conceivable [32].

This approach is theoretically possible each time a transdominant negative protein is available.

\subsection{Special vectors for transgene expression}

Transgenes containing regulatory elements of animal genes may be regulated in 


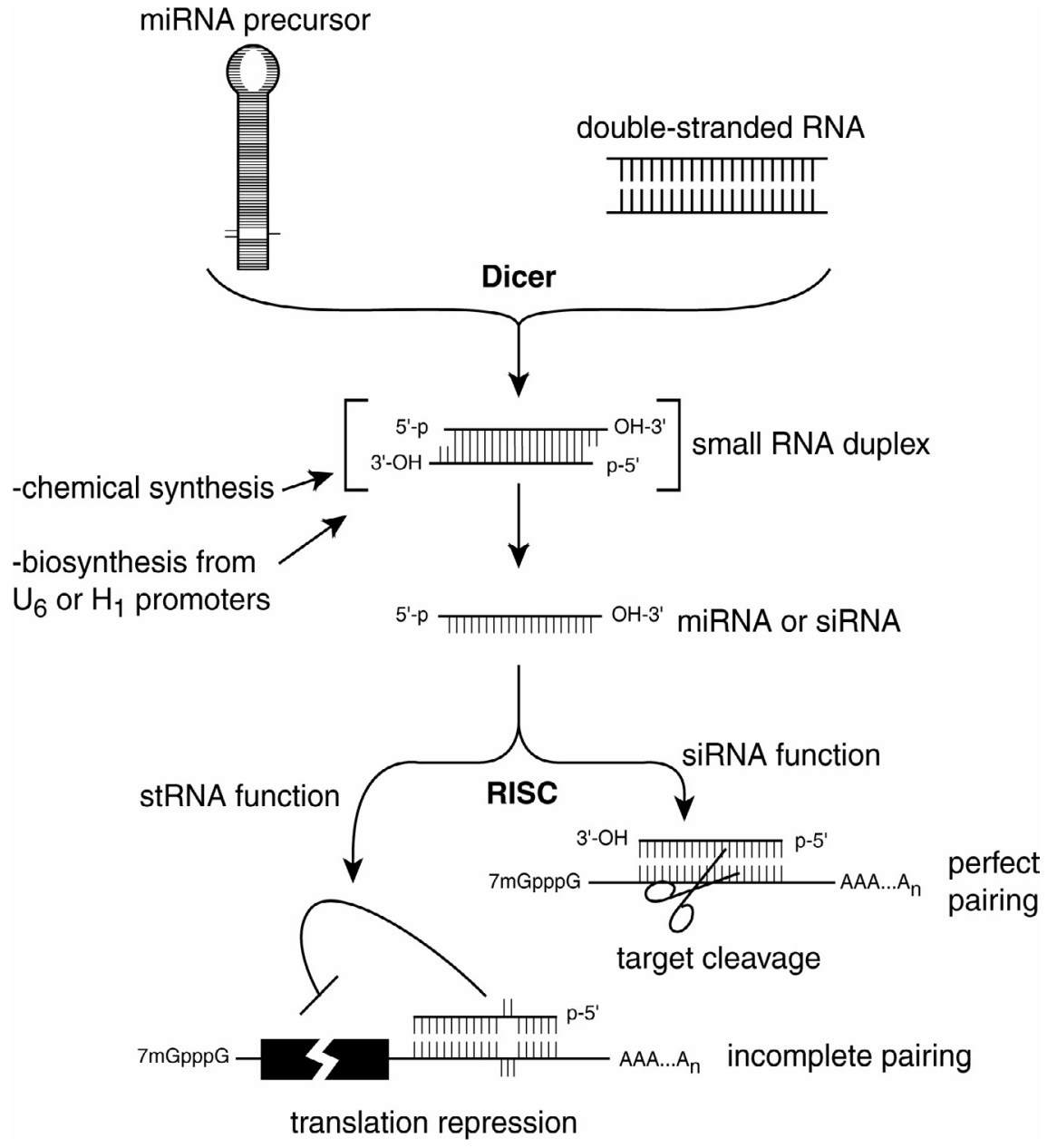

Figure 6. The mechanism of the inhibition of gene expression using interfering RNA (RNAi). Chemically synthesised small RNAi targeting a given cellular mRNA may be added to cells or generated in cells or animals by transgenes coding for these RNAi. The targeted RNA are specifically knock down.

a specific way in vivo. Yet, in some circumstances it may be important to induce or deinduce a transgene using unducers not acting on host genes.

Several systems are available to reach this goal. The most popular is based on the use of tetracyclin or analogues to induce expression of transgenes to which a control element sensitive to a tetracyclin repressor has been added. In practice, one transgenic line harbours the gene coding for a fusion protein containing the tetracyclin repressor and an animal gene activator. A second transgenic line harbours the gene of interest under the control of a tetracyclin repressor regulatory element. Tetracyclin added to the water of hybrid animals harbouring both transgenes induces the gene of interest in a 
reversible manner. In some circumstances, this method greatly improves the relevance of the transgenic models. It may render possible the study of a transgene which codes for a protein too deleterious for cells to be expressed permanently.

A family of vectors has been designed to trap unknown genes or promoters having an impact on a biological function. These vectors may contain a reporter gene devoid of an intron. The random integration of such a vector is performed in ES cells further used to generate transgenic mice. In some cases, the integration of the vector is followed by expression of its reporter gene and the alteration of a biological function in animals. This may mean that the integration of the vector occurred in a host gene which plays an important role in the altered function. The targeted gene may be identified using the reporter gene as a marker.

Gene trapping is a somewhat laborious method which may lead to the establishment of unpredictable correlations between the action of a gene and a biological function.

\section{THE APPLICATIONS AND THE FUTURE OF ANIMAL TRANSGENESIS}

A vast majority of transgenic animals are used to study gene action and function. The systematic sequencing of an increasing number of genomes renders the use of transgenesis still more necessary.

DNA integrated into an animal genome is quite stable and transmitted to progeny essentially without any modification. Transgene expression is also relatively reproducible in the different animals of a given line. It remains that up to $7-20 \%$ of host genes are interrupted and inactivated by the integration of a foreign gene [33]. Gene targeting and more generally reliable expression vectors would greatly reduce most of the artefacts due to the random integration of foreign genes.

Transgenic animals are a potent tool to generate models for the study of human diseases [34]. Mice which do not live more than two years have a negligible chance to spontaneously develop Alzheimer disease. The transfer of three human genes into mice led to the creation of a relevant model for the study of the disease and the evaluation of new pharmaceuticals.

The relevance of the models is highly dependent on an appropriate transgene expression as well as on gene replacement by homologous recombination. The mouse is the most frequently used species for this purpose but in some cases other species are required. This is the case when surgical operations such as organ grafting is being achieved. Rats or rabbits are then more appropriate. In some cases, animals like rabbits are preferred to mice for biological reasons. Indeed, lipid metabolism is more easily studied in rabbits than in mice since the former are closer to humans than the latter.

More than 50 lines of transgenic mice are available and can be purchased as other lines.

Experimenters wish to use more and more precise models. This implies that transgene expression be well-controlled and that gene replacement can be performed in several species. Technical progress in gene transfer and transgene expression is still needed to reach this goal.

It becomes more and more likely that pig organs and cells will be some day used for transplantation to patients. Quite encouraging results have been recently obtained. The knock out of the galactosyl transferase gene in the pig resulted in the absence of the most potent antigen at the surface of pig cells. This allowed kidneys from the transgenic pigs to be maintained healthy in experimental primates for at least two months.

Production of pharmaceutical proteins in the milk of transgenic animals is progressively becoming a reality. One protein, human antithrombin III, is currently under evaluation by the European agency EMMA. 
Many other proteins and mainly chimaeric; humanised or human monoclonal antibodies are expected to be produced at a moderate cost in the coming decade and later [35].

Applications of transgenes to improve animal production are still rare and none of these new products are on the market. This is clearly due to the difficulty and the cost of generating transgenic farm animals. The recent technical progress and particularly the implementation of cloning to add or replace genes offers quite attractive possibilities.

Among the project in course, a few of them can be mentioned. Transgenic fish, and mainly salmons, having an accelerated growth are on the way for authorisation to be used for human consumption. The problem of the possible dissemination into oceans has not been solved yet [36, 37].

Pigs expressing bacteria phytase in their saliva reject $75 \%$ less phosphate into the environment leading potentially to a significant reduction of pollution [38].

Goats or cows expressing an antibacteria protein such as human lysozyme, human lactoferrin or lysostaphin in their milk are expected to be less sensitive to mastitis. Their milk resists to corruption by bacteria infection and it might be used by persons suffering from bacteria infection [39, 40].

The struggle against diseases appears particularly interesting and technically feasible. Animals genetically resistant to diseases may need a lower use of pharmaceutical compounds including antibiotics. Their breeding may be facilitated and less costly. They may also reduce the possible transfer of animal diseases to humans. The resistance to Aujeszky disease appears as an interesting example.

Attempts to improve the quality of animal products appear attractive. This is the case for pigs expressing a desaturate gene from spinach which enhances the proportion of now saturated lipids [41].

A long study is still required to validate these lines of animals.

\section{REFERENCES}

[1] Houdebine LM. Animal Trangenesis and Cloning. Wiley and Sons, 2003, p 250.

[2] Dupuy AJ, Clark K, Carlson CM, Fritz S, Davidson AE, Markley KM, Finley K, Fletcher CF, Ekker SC, Hackett PB, Horn S, Largaespada DA. Mammalian germ-line transgenesis by transposition. Proc Natl Acad Sci USA 2002, 99: 4495-4499.

[3] Tamura T, Thibert C, Royer C, Kanda T, Abraham E, Kamba M, Thomas JL, Mauchamp B, Chavancy G, Shirp P, Fraser M, Prudhomme JC, Couble P. Germiline transformation of the silkworm Bombyx mori L. using a piggyBac transposon dervied vector. Nat Biotechnol 1999, 18: 81-84.

[4] Lois C, Hong EJ, Pease S, Brown EJ, Baltimore D. Germline transmission and tissue-specific expression of transgenes delivered by lentiviral vectors. Science 2002, 295: 868-872.

[5] Hofmann A, Kessler B, Ewerling S, Weppert M, Vogg B, Ludwig H, Stojkovic M, Boelhauve M, Brem G, Wolf E, Pfeifer A. Efficient transgenesis in farm animals by lentiviral vectors. EMBO Rep 2003, 4: 1054-1060.

[6] Hofmann A, Zakhartchenko V, Weppert M, Sebald H, Wenigerkind H, Brem G, Wolf E, Pfeifer A. Generation of transgenic cattle by lentiviral gene transfer into oocytes. Biol Reprod 2004, 71: 405-409.

[7] McGrew MJ, Sherman A, Ellard FM, Lillico SG, Gilhooley HJ, Kingsman AJ, Mitrophanous KA, Sang H. Efficient production of germline transgenic chickens using lentiviral vectors. EMBO Rep 2004, 5: 728-733.

[8] Koo BC, Kwon MS, Choi BR, Lee HT, Choi HJ, Kim JH, Kim NH, Jeon I, Chang W, Kim T. Retrovirus-mediated gene transfer and expression of EGFP in chicken. Mol Reprod Dev 2004, 68: 429-434.

[9] Whitelaw CB, Radcliffe PA, Ritchie WA, Carlisle A, Ellard FM, Pena RN, Rowe J, Clark AJ, King TJ, Mitrophanous KA. Efficient generation of transgenic pigs using equine infectious anaemia virus (EIAV) derived vector. FEBS Lett 2004, 571:233-236.

[10] Lavitrano M, Bacci ML, Forni M, Lazzereschi D, Di Stefano C, Fioretti D, Giancotti P, Marfe G, Pucci L, Wang H, Stoppacciaro A, Stassi G, Sargiacomo M, Sinibaldi P, Turchi V, Giovannoni R, Della Casa G, Seren E, Rossi G. Efficient production by sperm-mediated gene transfer of human decay accelerating factor (hDAF) transgeni cpigs for xenotransplantation. Proc Natl Acad Sci USA 2002, 99: 14230-14235. 
[11] Marsh-Armstrong N, Huang H, Berry DL, Brown DD. Germ-line transmission of transgenes in Xenopus laevis. Proc Natl Acad Sci USA 1999, 96: 14389-14393

[12] Moreira PN, Giraldo P, Cozar P, Pozueta J, Jimenez A, Montoliu L, Gutierrez-Adan A. Efficient generation of transgenic mice with intact yeast artificial chromosomes by intracytoplasmic sperm injection. Biol Reprod 2004, 71: 1943-1947.

[13] Kato M, Ishikawa A, Kaneko R, Yagi T, Hochi S, Hirabayashi M. Production of transgenic rats by ooplasmic injection of spermatogenic cells exposed to exogenous DNA: a preliminary study. Mol Reprod Dev 2004, 69: 153-158.

[14] Chang K, Qian J, Jiang M, Liu YH, Wu MC, Chen CD, Lai CK, Lo HL, Hsiao CT, Brown L, Bolen J Jr, Huang HI, Ho PY, Shih PY, Yao $\mathrm{CW}$, Lin WJ, Chen $\mathrm{CH}, \mathrm{Wu} \mathrm{FY}$, Lin YJ, Xu J, Wang K. Effective generation of transgenic pigs and mice by linker based sperm-mediated gene transfer. BMC Biotechnol 2002, 2: 1-13.

[15] Wang K, Improving sperm mediated transgenesis: linker based sperm gene transfer: application to multiple species with a high success rate. In: Transgenic Animal Research, Conference IV, Tahoe City USA, 2003, p. 31.

[16] Celebi C, Auvray P, Benvegnu T, Plusquellec D, Jegou B, Guillaudeux T. Transient transmission of a transgene in mouse offspring following in vivo transfection of male germ cells. Mol Reprod Dev 2002, 62: 477-482.

[17] Readhead C, Jarvis S, Morgan D, Winston R. Male germ cells: manipulating their genome. In: Transgenic Animal Research Conference IV, Tahoe City USA, 2003, p 11.

[18] Oatley JM, de Avila DM, Reeves JJ, McLean DJ. Spermatogenesis and germ cell transgene expression in xenografted bovine testicular tissue. Biol Reprod 2004, 71: 494-501.

[19] Capecchi MR. Altering the genome by homologous recombinaison. Science 1989, 244: $1288-1292$

[20] McCreath KJ, Howcroft J, Campbell KH, Colman A, Schnieke AE, Kind AJ. Production of gene-targeted sheep by nuclear transfer from cultured somatic cells. Nature 2000, 405: 1066-1069.

[21] Lai L, Kolber-Simonds D, Park KW, Cheong HT, Greenstein JL, Im GS, Samuel M, Bonk A, Rieke A, Day BN, Murphy CN, Carter DB, Hawley RJ, Prather RS. Production of alpha1,3-galactosyltransferase knockout pigs by nuclear transfer cloning. Science 2002, 295: 1089-1092.

[22] Dai Y, Vaught TD, Boone J, Chen SH, Phelps CJ, Ball S, Monahan JA, Jobst PM, McCreath
KJ, Lamborn AE, Cowell-Lucero JL, Wells KD, Colman A, Polejaeva IA, Ayares DL. Targeted disruption of the alpha1,3-galactosyltransferase gene in cloned pigs. Nat Biotechnol 2002, 20: 251-255.

[23] Kuroiwa Y, Kasinathan P, Matsushita H, Sathiyaselan J, Sullivan EJ, Kakitani M, Tomizuka K, Ishida I, Robl JM. Sequential targeting of the genes encoding immunoglobulin-mu and prion protein in cattle. Nat Genet 2004, 36: 775-780.

[24] Houdebine L, Attal J, Vilotte JL. Vector design for transgene expression. In: Carl A, Pinkert ED (Eds), Transgenic animal technology, 2nd ed, 2002, p 419-458.

[25] Giraldo P, Rival-Gervier S, Houdebine LM Montoliu L. The potential benefits of insulators on heterologous constructs in transgenic animals. Transgenic Res 2003, 12: 751-755.

[26] Mittal V. Improving the efficiency of RNA interference in mammals. Nat Rev Genet 2004, 5: 355-365.

[27] Novina CD, Sharp PA. The RNAi revolution. Nature 2004, 430: 161-164.

[28] Shinagawa T, Ishii S. Generation of Skiknockdown mice by expressing a long doublestrand RNA from an RNA polymerase II promoter. Genes Dev 2003, 17: 1340-1345.

[29] Schramke V, Allshire R. Those interfering little RNAs! Silencing and eliminating chromatin. Curr Opin Genet Dev 2004, 14: 174-180.

[30] Morris KV, Chan SW, Jacobsen SE, Looney DJ. Small interfering RNA-induced transcriptional gene silencing in human cells. Science 2004, 305: 1289-1292.

[31] Richardson JH, Marasco WA. Intracellular antibodies: development and therapeutic potential. Trends Biotechnol 1995, 13: 306-310.

[32] Ono E, Amagai K, Taharaguchi S, Tomioka Y, Yoshino S., Watanabe Y, Cherel P, Houdebine LM, Adam M, Eloit M, Inobe M, Uede T. Transgenic mice expressing a soluble form of porcine nectin-1/herpesvirus entry mediator $\mathrm{C}$ as a model for pseudorabies-resistant livestock. Proc Natl Acad Sci USA 2004, 101: 16150-16155.

[33] Van Reenen CG, Meuwissen TH, Hopster H, Oldenbroek K, Kruip TH, Blokhuis HJ. Transgenesis may affect farm animal welfare: a case for systematic risk assessment. J Anim Sci 2001, 79: 1763-1779.

[34] Houdebine LM. The mouse as an animal model for human diseases. In: Hedrich $\mathrm{H}$ (Ed), The laboratory mouse, 2004, p 656.

[35] Houdebine LM. Antibody manufacture in transgenic animals and comparisons with 
other systems. Curr Opin Biotechnol 2002, 13: 625-629.

[36] Muir WM, Howard RD. Assessment of possible ecological risks and hazards of transgenic fish with implications for other sexually reproducing organisms. Transgenic Res 2002, 11: 101-114.

[37] Howard RD, DeWoody JA, Muir WM. Transgenic male mating advantage provides opportunity for Trojan gene effect in a fish. Proc Natl Acad Sci USA, 2004, 101: 2934-2938.

[38] Golovan SP, Meidinger RG, Ajakaiye A, Cottrill M, Wiederkehr MZ, Barney DJ, Plante C, Pollard JW, Fan MZ, Hayes MA, Laursen J, Hjorth JP, Hacker RR, Phillips JP, Forsberg CW. Pigs expressing salivary phytase produce lowphosphorus manure. Nat Biotechnol 2001, 19: 741-745.
[39] Kerr DE, Plaut K, Bramley AJ, Williamson CM, Lax AJ, Moore K, Wells KD, Wall RJ. Lysostaphin expression in mammary glands confers protection against staphylococcal infection in transgenic mice. Nat Biotechnol 2001, 19: 66-70.

[40] Murray J, Reh W, Anderson G, Maga E. Changing the composition of milk to improve human health. In: Transgenic Animal Research, Conference IV, Tahoe City California, 2003, p 32.

[41] Saeki K, Matsumoto K, Kinoshita M, Suzuki I, Tasaka Y, Kano K, Taguchi Y, Mikami K, Hirabayashi M, Kashiwazaki N, Hosoi Y, Murata N, Iritani A. Functional expression of a Delta12 fatty acid desaturase gene from spinach in transgenic pigs. Proc Natl Acad Sci USA 2004, 101: 6361-6366. 